\title{
Online Advertising: An Investigation of Factors Affecting Positive Attitude among the Malays in Malaysia
}

\author{
Mehdi Taghipoorreyneh \\ Faculty of Economics and Business, Universiti Malaysia Sarawak, Malaysia. \\ Ernect Cyril De Run \\ Faculty of Economics and Business, Universiti Malaysia Sarawak, Malaysia
}

\begin{abstract}
The aim of this research is to inestigate about attitudes toward online advertising (ATOA) among Malays. Data were collected from Malays above eighteen years old with Internet usage experiences. Four belief factors that underline Malays consumers' attitudes toward online advertising were identified: informativeness, hedonism, credibility and good for economy. The findings from this research indicated that informativeness, hedonism and good for economy had significant impacts on ATOA among Malays. The research provides potentially useful insights and directions for marketers in order to optimize the results of their online advertising campaigns among Malays in Malaysia.
\end{abstract}

Keywords: Attitudes, Credibility, Good for Economy, Hedonism, Informativeness, Online Advertising 


\section{Introduction}

As the Internet has increasingly become an integrated tool for marketing and advertising, the effectiveness of online advertising remains a crucial yet debatable issue among marketers and advertisers. Past studies have mentioned that individuals' attitudes toward online advertising are an important factor that enables for evaluation of advertising effectiveness (Ducoffe, 1996; Russell et al, 1994). With consumer confidence up and brands looking to reconnect, it's no surprise that spending on advertising is on the rise around the globe and across media types. According to advertising report by the Nielsen Company (2012) quarter one, online ads spend was a bright spot for the various industries. Growth was particularly notable in Europe (12.1\%), Latin America (31.8\%) and the Middle East and Africa (35.2\%). In Malaysia increasing ad spend, however, was seen in the media with a smaller share of voice such as internet $(+12.2 \%)$ compare with the same quarter in 2011 .

In spite of this rapid mainstreaming of online advertising around the globe, many marketers still are not observing a range of basing tactics and strategies comprehended to considerably improve the effectiveness of online advertising campaigns in a foriegn and specific market. In some cases, this is because advertisers aren't aware of the attitudinal differences when going into new markets. This is particularly true for South East Asian countries that have their own different languages, cultures and business environment that are very different from the Western countries. These factors, together with the associated legal limitation to protect cultural identity and limitation of any offence to cultural group have been observed as a main area of involving for marketers entering these markets (Shao and Waller, 1993). The potential for online advertising within the local area had yet to fully comprehend and there are great opportunities for growth.

However, there is still very little research being performed on how consumer values in distinctive ethnic cultures affect consumer behaviour, specifically among the South East Asian (Tan and McCullough, 1985; Ward et al, 2002). The bulk of researches in consumer behaviour context have mostly been Western bias (Mooij, 2003). In those researches, differences were illustrated in consumption patterns between people of different ethnic groups (Saegert et al, 1985). Recently, there have been some studies on the South Asian ethnic cultures such as the Japanese, the Koreans and the Chinese. It is worthy of notice to indicate that these countries are greatly racially homogenous. This is very dissimilar Malaysia where we see the side-by-side harmonious living of different races such as the Malay, the Chinese, the Indians and other minority ethnic groups with distinctive and different cultures within a single social system. It is in this context that Malaysia provides a good platform to further study on consumer behaviour specifically with its cultural diversity.

The term ethnicity and its effect in advertisement effectiveness first appeared in the seminal work of Deshpande et al (1986). Ethnic marketing study is driven by the assumption that ethnicity can influence a wide range of consumer behaviour (Burton, 2000). Following from the above, the present study's objective is to examine attitudes towards online advertising among Malays consumers as the largest ethnic group in Malaysia. According to Worldometer 2016 population census, the total population of Malaysia is nearly 31 million. $50.3 \%$ of Malaysia's population are of Malay ethnicity, whereas $21.8 \%$ are of Chinese ethnicity and $6.5 \%$ are of Indian ethnicity (Department 
of Statistics Malaysia, 2015). Malay as defined in article 160(2) of the Malaysian constitution is a person who professes Islam, habitually speaks the Malay language and conforms to Malay customs (Asma and Pedersen, 2003).

\section{Antecedents of Attitude toward Online Advertising (ATOA)}

In a consumer behaviour context Schiffman and Kanuk (2004) defined attitude as 'a learned predisposition to behave in a constantly favourable or unfavourable way with respect to a given object.' This definition indicates that attitude is neither innate nor instinctive, but rather can be influenced by marketing messages. Furthermore, when someone changes his behaviour each time, he does not hold and attitude toward an object.

Consumers' belief and attitudes toward advertising are important indicators of advertising effectiveness (Mehta, 2000). Presently, there exist two typical views about the relationship between consumers' beliefs and their general attitudes toward advertising. The first treats the two constructs as equivalent and interchangeable, both conceptually and operationally (Mehta, 2000; Schlosser and Shavitt, 1999), whereas the second postulates that beliefs are antecedents of attitude and these two things are separate from each other (Brackett and Carr, 2001; Fishbein, 1967). In this study, our model is built upon the second perspective.

Most studies trying to measure attitude toward online advertising extract their theoretical frameworks from previous studies of attitude toward advertising in general (Burns, 2003; Cowley et al, 2000). Based on previous studies, determinants such as hedonic, product information, good for economy and credibility consistently indicate strong relationship with consumers' attitude towards advertising (Sadeghvaziri and Seyedjavadian, 2011; Kwek et al, 2010; Petrovici et al, 2007; Zhang and Wang, 2005). Wang et al (2009) used information seeking, value corruption, entertainment, good for economy and credibility as main antecedent of attitude toward online advertising. On this basis, the present study also proposes a model of online advertising based on the traditional advertising model.

\section{Informativeness (INF)}

A key role of advertising is to generate awareness of products and to make consumer aware of how competing products are different (Soberman, 2004). One of the advertising purposes is to make customers aware of new products or new features of existing products also inform them about changes in products' price (Kotler and Keller, 2009).

Previous researchers examined that the information-seeking factor acts as a positive predictor for the forming of consumers' attitude towards online advertising (Wang and Sun, 2010; Wang et al, 2009).Albion and Farris (1981) supported that the positive roles of advertising as a source of product information generates many benefits as producing "competition", promoting "new product and brand entry", and aiding "consumer shopping". Based on the previous literature, the following hypothesis is formulated: 
H1: There is positive relationship between informativeness and attitude toward online advertising among Malays.

\section{Hedonism (HED)}

Hedonism is essential that the message is concise and funny, and can be captures consumers' attention (Katterbach, 2002). People's feeling of pleasure related with advertisements play the greatest role in accounting for their attitudes toward them in general (Shavitt, 1998). The degree of entertaining of advertising information is significant to advertising delivered. The entertaining advertising message could influence on the attitudes towards it. Consumers like and prefer to see advertisements that have more entertainment and pleasurable elements, the more the pleasure the better it is (Pollay and Mittal, 1993; Alwitt and Prabhaker 1992).

Saadeghvaziri and Seyedjavadian (2011) found that hedonism and entertainment of advertising leads positive attitude toward mobile advertising among students in Iran. Kwek et al (2010) demonstrated that there is positive relationship between hedonism and attitude toward advertising among students. Tsang and Tse (2005) demonstrated that the Hedonic factor is significantly important in effective Web marketing. Entertainment services can add value for the customer and increase customer loyalty (Haghirian and Dickinger, 2004). By applying these we hypothesized:

$\mathbf{H}_{2}$ : There is positive relationship between hedonic and attitude toward online advertising among Malays.

\section{Good for Economy (ECO)}

The concept of good for economy reflects the point of view that advertising speeds up the adoption of new goods and technologies by consumers (Belch and Belch, 2009). The economic benefit of advertising is the skill of the advertisers to provide precise and credible information about their products or services to the viewers (Petrovici et al, 2007). Good for economy of an advertising message was positively related to consumers' attitude towards advertising (Kwek et al, 2010). Wang et al (2009) concluded that good for economy is positively related to Chinese consumers' attitude towards online advertising.. Other researchers support that good for economy of an advertising message positively influence consumers' attitude towards advertising (Munusamy and Wong, 2007; Tan and Chia, 2007). By applying these we hypothesized:

H3: There is positive relationship between good for economy and attitude toward online advertising among Malays.

\section{Credibility (CRE)}

Advertising credibility is "consumers' perception of the truthfulness and believability of advertising in general" (Mackenzie and Lutz, 1989).Wang et al (2009) concluded there was not significant relationship between credibility of online advertising and attitude toward online advertising among Chinese Consumers. Munusamy and Wong (2007) examined that there is positive relationship between credibility and students attitude toward advertising in private universities in Selangor Malaysia. Wang et al. 
(2011) found Romanian are more likely to view online advertising as reliable source of information. Therefore, the following hypothesis is proposed :

H4: There is positive relationship between credibility and ATOA among Malays.

\section{Conceptual Framework}

The conceptual framework was designed with the dependent variable attitude towards online advertising(ATOA) being influenced positively or negatively by the independent variables, based on these conjectures and the arguments to support the conjectures. The independent variables include, Informativeness (INF), Hedonic (HED), Good for economy (ECO), and Credibility (CRE) (see Figure 1). These were developed based on the review of relevant literature.

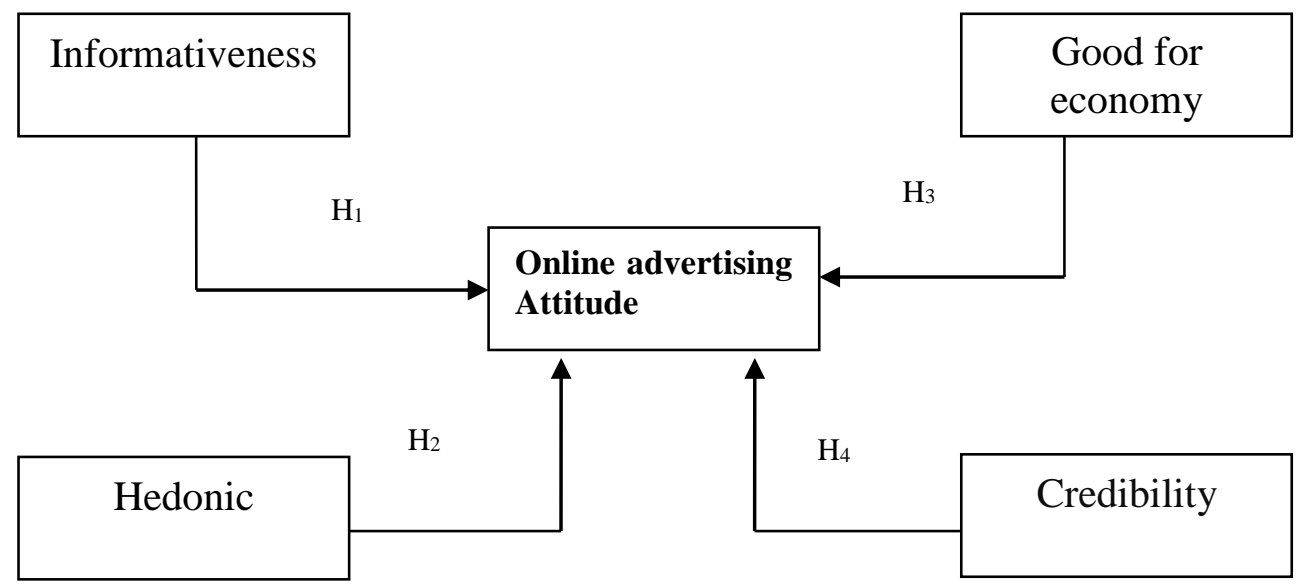

Figure 1: Conceptual Framework

\section{Research Methodology}

The population consisted of adults above 18 years old with Internet usage experience from the Malays in Malaysia. Overall, 351 questionnaires were collected from Malays. 37 surveys were excluded from the sample because of the large amount of missing data. Finally, a total of 314 questionnaires were subjected to data analysis. Data were collected through structured questionnaire. Personally surveys were conducted in Kelang Valley area to obtain information directly from individuals. No intensive was provided for respondent to complete the questionnaire.

To measure subjects' beliefs about online advertising, a 16-item was adapted from previous studies (Pollay and Mittal, 1993; Yang, 2004). The scale consisted of items pulled from different dimensions of beliefs including informative (e.g., the Internet is a valuable source of information), good for consumers (e.g., Online advertising is essential) and hedonic (e.g., Online advertising is entertaining and enjoyable), credible (trustworthy and believable) and attitude toward online advertising. Responses were measured on a 5-point Likert scale ranging from 1 (strongly disagree) to 5 (strongly agree). 


\section{Research Findings}

For the Malays sample, respondents $69.2 \%$ were male and $30.8 \%$ were female. Fiftysix $(56 \%)$ percent of Malaysian range in age were between 18 to 26 years. More than half of respondents visited online websites multiple times during a day and spend more than 57 minutes in each connection. Descriptive statistics of the belief items are presented in Table1.

Table 1: Items of belief factor

\begin{tabular}{lcc}
\hline Online advertising... & $M$ & $S D$ \\
\hline 1.My general opinion of online advertising is favorable & 3.76 & .870 \\
2. Tells me which brands have the features I am looking for & 3.04 & .764 \\
3. It is a good source of product information & 3.01 & .762 \\
4. Provides timely information. & 3.06 & .793 \\
5. Makes product information immediately accessible. & 3.07 & .838 \\
6. Is often amusing and entertaining & 3.13 & 1.098 \\
7.Is enjoyable & 3.30 & .922 \\
8. Is sometimes even more enjoyable than other media contents. & 3.31 & .855 \\
9. Gives me pleasure when I think about what I saw or heard or & 3.47 & .846 \\
10.In general helps our nation's economy & 3.03 & .778 \\
11.Generally helps the local economy & 3.04 & .786 \\
12. Helps raise our standard of living & 3.27 & .993 \\
13.Advertising in general is truthful & 3.25 & .949 \\
14.I use online advertising as a reference for purchasing & 3.53 & .800 \\
15.Advertising is not exaggerating products & 3.63 & .837 \\
16.I'm frequently misled by advertising & 3.37 & 1.044 \\
\hline
\end{tabular}

Principal axis factor analysis with Promax rotation through SPSS 17 was conducted to examine the underlying structure of those 15 items measuring beliefs about advertising. The KMO was 0.741 , indicating that the sampling adequacy which should be greater than 0.5 for satisfactory factor analysis to proceed was acceptable. Bartlets test was significant whit a chi sq of $2367.809(\mathrm{p}=0.00)$. Factor loadings are presented in Table 2.

Table2: Rotated component matrix for belief factor toward ATOA ${ }^{\mathrm{a}}$

\begin{tabular}{lllll}
\hline \multicolumn{5}{c}{ Component } \\
Variables & INF & CRE & HED & ECO \\
\hline INF1 & .894 & & & \\
INF2 & .874 & & & \\
INF3 & .925 & & & \\
INF4 & .790 & & & \\
CRE1 & & .833 & & \\
CRE2 & & .839 & & \\
CRE3 & & .885 & & \\
CRE1 & & .833 & & \\
HED1 & & & .618 & \\
HED2 & & & .891 & \\
HED3 & & & .916 & \\
HED4 & & & .564 & \\
\hline
\end{tabular}


Table2: Rotated component matrix for belief factor toward ATOA $^{\mathrm{a}}$ (Cont'd)

\begin{tabular}{lllll}
\hline & \multicolumn{2}{c}{ Component } & \multicolumn{2}{l}{ Component } \\
\hline Variables & INF & Variables & INF & Variables \\
\hline ECO2 & & & & .741 \\
ECO3 & & & & .776 \\
ECO4 & & & .767 \\
\hline Eigenvalues & 3.388 & 3.170 & 2.253 & 1.710 \\
\% of Variance & 22.585 & 21.132 & 15.019 & 11.402 \\
Cumulative \% & 22.585 & 43.717 & 58.736 & 70.139 \\
Alpha & .894 & .872 & .757 & .669 \\
\hline
\end{tabular}

Extraction Method: Principal Component Analysis.

Rotation Method: Promax with Kaiser Normalization.

a. Rotation converged in 5 iterations.

Table 3 reveals the correlation matrix of the conceptual variables. A two-tail test at 0.05 significant levels indicates that there are positive correlations among the independent variables and the dependent variable.

Table 3: Pearson correlation coefficient matrix

\begin{tabular}{lccccc}
\hline & ATOA & INF & CRE & HED & ECO \\
\hline ATOA & 1.000 & & & & \\
INF & .075 & 1.000 & & & \\
CRE & $.168^{* *}$ & .093 & 1.000 & & \\
HED & $.266^{* *}$ & $-.128^{*}$ & .017 & 1.000 & \\
ECO & $.676^{* *}$ & -.039 & $.184^{* *}$ & $.115^{*}$ & 1.000 \\
\hline
\end{tabular}

**. Correlation is significant at the 0.01 level (2-tailed).

*. Correlation is significant at the 0.05 level (2-tailed).

Table 4 shows $\mathrm{R}=0.714$ and $\mathrm{R} 2$ value $=0.510$. This means that $51.0 \%$ of the variation in $\mathrm{Y}$ can be explained by all predictors (or accounted for by) the variation in $\mathrm{X}$ Regression coefficients of three out of four positive belief factors such as information seeking, economy and hedonism beliefs significantly and positively predict ATOA among Malays. Credibility, however, did not emerge as significant predictors of ATOA among Malays. 
Table 4: Regression Weights

\begin{tabular}{|c|c|c|c|c|c|c|}
\hline \multirow{2}{*}{\multicolumn{2}{|c|}{ Model }} & \multicolumn{2}{|c|}{ Unstandardized Coefficients } & \multirow{2}{*}{$\begin{array}{c}\text { Standardized } \\
\text { Coefficients }\end{array}$} & \multirow[b]{2}{*}{$\mathrm{T}$} & \multirow[b]{2}{*}{ Sig. } \\
\hline & & $\mathrm{B}$ & Std. Error & & & \\
\hline \multirow[t]{6}{*}{1} & (Constant) & 3.761 & .035 & & 108.657 & .000 \\
\hline & INF & .107 & .035 & .123 & 3.048 & .003 \\
\hline & CRE & .029 & .035 & .033 & .819 & .413 \\
\hline & HED & .179 & .035 & .206 & 5.096 & .000 \\
\hline & ECO & .567 & .036 & .651 & 15.943 & .000 \\
\hline & & $\mathrm{R}$ & $\mathrm{R}^{2}$ & $\operatorname{Adj} R^{2}$ & $\mathrm{~F}$ & \\
\hline \multicolumn{2}{|c|}{ Model 1} & $.714^{\mathrm{a}}$ & .510 & .503 & $80.289 * *$ & \\
\hline
\end{tabular}

\section{Discussion and Conclusion}

This research indicated four common belief factors across the Malay samples: hedonism, information, credibility and economy. According to the findings, informativeness of advertising leads to a positive attitude toward online advertising among Malays. Prior studies have been found the importance of mobile advertising informativeness (Saadeghvaziri and Seyedjavadain, 2011) and the importance of informativeness toward advertising attitude in general (Munusamy, 2007). It is not surprising that those consumers who perceive that online advertising provide needed information have a more favourable attitude toward online advertising. Internet use motivation research reveals that information seeking is the primary reason people use the internet (Rubin, 2002). One reason could be the interaction nature of online advertising that allows consumers to acquire real-time account information that was not in the past (Stewart and Pavlou, 2002). Therefore, advertising with information produce greater marketplace competences in Malaysia, as the target customers are better able to match their needs and wants versus a producer' offerings (Pollay and Mittal, 1993).

The effect of the hedonism has been confirmed among the Malays. This is consistent with the previous studies. As Wang et al (2009) noted entertainment of the advertising is significantly related to consumer attitude toward online advertising. Also according to Munusamy (2007) there is positive relationship between entairtenment and attitude toward advertising among Malaysians. Marketers should also think about hedonism/pleasure as an important way to increase consumers' advertising likeability. Characteristics such as humor, enjoyable messages can easily attract consumers' attention. Bauer and Greyser (1968) shown that people might enjoy watching and hearing advertisings with hedonism/pleasure without thinking about their interest in what is advertised. A more clear comprehension of the influence of hedonism/pleasure on attitude would benefit marketers in that they could design ad campaigns that emphasize hedonism/pleasure to create positive feelings from a market segment.

Good for economy of advertising results in positive attitude toward online advertising among Malays, which is consisted with previous study about attitude toward 
advertising (Towler, 2001). It means, the more positive belief in good for economy, the more positive are customers' attitude towards online advertising. Companies employ people who make products and provide the services that advertising sells (Belch and Belch, 2009). Therefore, it does make sense that people believe online advertising is good for their economy (Wang et al, 2009, Wang and Sun, 2010).

Based on the findings credibility is not significant predictor for Malays consumers. Previous researches indicated different results. Zhou et al (2002) have supported the credibility of advertising while Beard (2003) has criticized the credibility of advertising. The findings suggest that Malays could be more open to receive information but they are also more skeptical of information in online advertising. Over the past decade, Malaysia has seen rapid growth and expansion of information technology and communication (Kaur, 2005). The Internet has allowed a gushing stream of information to flow into the land and as such it is not surprising that Malay belief would be affected by the availability of such information. In spite of an influx of usage on the online media. Security-related issues were cited as the main reason for not shopping online (Kaur, 2005). It has been shown that consumers in emerging markets often hold deep concern about the trustworthiness of online advertising due to the immaturity of the market and a lack of regulation systems (Wolin et al., 2002). To establish credibility of online advertising, researchers have suggested that marketers should consider strategies such as money-back guarantees, improved customer services, and affiliations with credible organizations for a "seal of approval"' (Wolin et al., 2002).

This research contributes to the knowledge in two important areas of consumer behaviour research. Firstly, it advances to a better understanding of consumer attitudes in Malaysia. Secondly, it enhances the understanding of how ethnicity background influences general attitudes towards online advertising.

\section{Limitations and Suggestions for Future Research}

A few caveats are worth noting about the current research, which suggest areas to consider for future research. It was beyond the scope of this study to examine the relationship of attitude toward online advertising and other aspects of beliefs toward online advertising, including social and legal issues. Understanding the criteria consumers use to determine whether advertising is generally positive or negative would be valuable. Future research may also consider including respondents from other states including East Malaysia. This research does not consider non-internet users' attitude toward online advertisement.

\section{References}

Albion, M. S. and Farris, P. W. (1981), The advertising controversy: Evidence on the economic effects of advertising, Boston: Auburn House Publishing Co.

Alwitt, L. F., and Prabhaker, P. R. (1992), "Functional and beliefs dimensions of attitudes to television advertising: Implications for copytesting", Journal of Advertising Research, Vol. 32, no.5, pp. 3042.

Asma, A. (1982), Language and Society in Malaysia, Dewan Bahasa Dan Pustaka, Kuala Lumpur. 
Beard, F. K. (2003), "College student attitudes toward advertising's ethical, economic, and social consequences", Journal of Business Ethics, vol. 48, no. 3, pp.217.

Belch, G., and Belch, M. (2009), Advertising and promotion: An integrated marketing communication perspective, Irwin, CA: McGraw-Hill.

Brackett, L., and Carr, B. (2001), "Cyberspace advertising vs. other media: Consumer vs. mature student attitudes", Journal of Advertising Research, vol. 41, pp. 23-32.

Burns, K. S. (2003), Attitude toward the online advertising format: A reexamination of the attitude toward the ad model in an online advertising context, unpublished doctoral dissertation, University of Florida, Gainesville.

Burton, D. (2000), "Ethnic identity and marketing: a critical review", Journal of Marketing Management, Vol. 16, no. 1, pp. 853-77.

Cowley, E., Page, K., and Handel, R. H. (2000), "Attitude toward advertising implications for the World Wide Web" Proceedings of Australian and New Zealand Marketing Academy Conference, pp. 463-467.

Department of statistic Malaysia (2015), Retreived from: https://www.statistics.gov.my/index.php?r=column/cpublication\&menu_id=S2E5Zkl hckxmejVSaFFJb29acXZvUT09.

De Run, E. (2004), Unintended effects of ethnically targeted advertising, University of Otago, Dunedin.

Deshpande, R., Hoyer, D. and Donthl, N. (1986), "The intensity of ethnic affiliation: a study of the sociology of Hispanic consumption", Journal of Consumer Research, vol. 13, no. 2, pp. 214-20.

Ducoffe, R. (1996), "Advertising value and advertising on the web", Journal of Advertising Research, vol. 36, no. 5, pp. 21-35.

Fishbein, M. (1967), Attitude and the prediction of behavior, In: Fishbein, M. and Ajzen, I. (1975) Belief, attitude, intention and behaviour: An introduction to theory and research. California: Addison-Wesley.

Greyser, S. A. and Bauer, R. A. (1968), Advertising in America: The consumer view, Boston:Harvard University, Graduate School of Business Administration, Division of Research.

Haghirian, P., Dickinger, A. (2004), "identifying success factors for mobile marketing: a conceptual model", Asia Pacific ACR Conference, Seoul, Korea.

Katterbach, W. (2002), Die SMS-Verkäufer, Impulse, February 1st, 2002(76).

Kaur, K. (2005), „Consumer Protection in E-Commerce in Malaysia: An Overview. UNEAC Asia Papers, 10", Retrieved from http://www.une.edu.au/asiacenter/kkaur.pdf.

Kotler, P., Keller, K., Brady, M., Goodman, M., and Hansen, T. (2009), Marketing management, 12th edition. New York: Pearson Prentice Hall.

Kwek, C. L., Tan, H. P. and Lau, T. C. (2010), "The determinants of consumers' attitude towards advertising", Canadian Social Science, vol. 6, no. 4, pp. 114-126.

Mackenzie, S.B., and Lutz, R.J. (1989), "An empirical examination of the structural antecedents of attitude toward the ad in an advertising pretesting context" Journal of Marketing, vol. 53, no. 2, pp. 48-65

Mehta, A. (2000), "Advertising attitudes and advertising effectiveness, Journal of Advertising Research, vol. 40, no. 3, pp.67-72.

Mooij,M. (2003), Consumer behaviour and culture: Consequences for global marketing and advertising, Thousand Oaks, CA, USA: Sage Publications Inc, pp. 306.

Munusamy, J. and Wong, C. H. (2007), "Attitude towards advertising among student at private higher learning institutions in Selangor" Journal of UNITAR, vol. 3, no. 1, pp. 35 .

Petrovici, D., Marinova, S., Marinov, M. and Lee, N. (2007), "Personal uses and perceived social and economic effects of advertising in Bulgaria and Romania", Journal of International Marketing Review, vol. 24, no. 5, pp. 539-562.

Pollay, R. W. and Mittal, B. (1993), "Here's the beef: factors, determinants, and segments in consumer criticism of advertising", Journal of Marketing, vol. 57, no. 3. pp. 99-114 
Rubin, Alan M. (2002), "The Uses-and-Gratifications Perspective of Media Effects" In Jennings Bryant and DolfZillman, eds., Media Effects: Advances in Theory and Research, 2nd ed., pp. 525-48. Mahwah, NJ: Erlbaum.

Russell, H., Staffaroni, J. and Fox, A. (1994), "The missing measures of copy testing", Journal of Advertising Research, vol. 34, no. 3, pp. 46-56.

Saadeghvaziri, F. and Seyedjavadain, S. (2011), "Attitude toward Advertising: Mobile Advertising Vs Advertising-in-General”, European Journal of Economics, Finance and Administrative Sciences, no 28 .

Saegert, J., R.J. Hoover and M.T. Hilger (1985), "Characteristics of Mexican American Consumers," Journal of Consumer Research, vol. 12, pp. 104-109.

Schiffman, L.G. and Kanuk, L.L. (2004), Consumer behavior, 8th ed., Pearson: Prentice Hall.

Schlosser, A. E., Shavitt, S. and Kanfer, A. (1999), "Survey of Internet users' attitudes toward Internet advertising", Journal of Interactive Marketing, vol. 13, no. 3, pp. 34-54.

Shao, A.T and Waller, D.S. (1993), Advertising standardization in the Asia pacific region: what stands in the way?" Asia Pacific Journal of Marketing and Logistic, vol. 5, no. 3, pp. 43-55.

Shavitt, S., Lowrey, P., and Haefner, J. (1998), "Public attitudes toward advertising: More favorable than you might think", Journal of advertising research, vol. 38, no. 4, pp. 7-22.

Soberman, D. A. (2004), "Research Note: Additional Learning and Implications on the Role of Informative Advertising", Management Science, vol. 50, no. 12, pp. 1744-1750

Stewart, D. W. and P. A. Pavlou (2002), "From consumer response to active consumer: measuring the effectiveness of interactive media" Journal of the Academy of Marketing Science, vol. 30, no. 4, pp.376 - 396.

Tan.C.T, and McCullough. J. (1985), "Relating ethnic attitudes and consumption values in an Asian context", Advances in Consumer Research, vol. 12, pp. $122-125$.

Tan, S. J. and Chia, L. (2007), "Are we measuring the same attitude? Understanding media effects on attitude towards advertising", vol. 7, no. 4. Retrieved from http://mtq.sagepub.com/cgi/content/abstract/7/4/353.

Tsang, P., and Tse, S. (2005), "A hedonic model for effective web: An empirical examination”, Industrial Management and Data Systems, vol. 105, no. 8, pp. 1039 1052.

Wang, Y., and Sun, S. (2010), "Assessing beliefs, attitudes, and behavioral responses toward online advertising in three countries", International Business Review, vol. 19, pp. 333-344.

Wang, Y., Sun, S., Lei, L., and Toncar, M. (2009), "Examining beliefs and attitudes toward online advertising among Chinese consumers", Direct Marketing: An International Journal, vol. 3, no. 1, pp. 52-66.

Ward.S, Pearson. C, and Entrekin .L, (2002), "Chinese cultural values and the Asian meltdown”, International Journal of Social Economics, Bradford, vol. 29, no. (3/4), pp. 205-218.

Wolin, L., Korgaonkar, P. and Lund, D. (2002), "Beliefs, attitudes and behavior towards web advertising ", International Journal of Advertising, vol. 21, no. 1, pp. 87-113.

Yang, K. (2004), "A comparison of attitudes towards internet advertising among lifestyle segments in Taiwan", Journal of Marketing Communications, Vol. 10, pp. 195-212.

Zhang, P and Wang, C. (2005), An empirical study on consumer's perceived value and attitude toward advertising, Research presented at the Global Information Technology and Management (GITM) World Conference, Anchorage, AK.

Zhou, D., Zhang, W. and Vertinsky, I. (2002) 'Advertising trends in urban China' Journal of Advertising Research, vol. 42, no. 3, pp.73-81. 